\title{
Four-quadrant flyback converter for direct audio power amplification
}

\author{
Ljusev, Petar; Andersen, Michael Andreas E.
}

Published in:

11th European Conference on Power Electronics and Applications

Link to article, DOI:

10.1109/EPE.2005.219419

Publication date:

2005

Document Version

Publisher's PDF, also known as Version of record

Link back to DTU Orbit

Citation (APA):

Ljusev, P., \& Andersen, M. A. E. (2005). Four-quadrant flyback converter for direct audio power amplification. In 11th European Conference on Power Electronics and Applications IEEE.

https://doi.org/10.1109/EPE.2005.219419

\section{General rights}

Copyright and moral rights for the publications made accessible in the public portal are retained by the authors and/or other copyright owners and it is a condition of accessing publications that users recognise and abide by the legal requirements associated with these rights.

- Users may download and print one copy of any publication from the public portal for the purpose of private study or research.

- You may not further distribute the material or use it for any profit-making activity or commercial gain

- You may freely distribute the URL identifying the publication in the public portal

If you believe that this document breaches copyright please contact us providing details, and we will remove access to the work immediately and investigate your claim. 


\title{
Four-quadrant flyback converter for direct audio power amplification
}

\author{
Petar Ljušev and Michael A.E. Andersen \\ ØRSTED • DTU AUTOMATION, TECHNICAL UNIVERSITY OF DENMARK \\ Elektrovej DTU Building 325 \\ Kgs. Lyngby DK-2800, Denmark \\ Tel: +45 4525 3486, Fax: +45 45886111 \\ E-mail: pl@oersted.dtu.dk,ma@oersted.dtu.dk
}

\section{Acknowledgments}

The SICAM project is funded under the grant of the Danish Energy Authority EFP no. 1273/02-0001 and is performed in cooperation with Bang \& Olufsen ICEpower a/s in Kgs. Lyngby, Denmark.

\section{Keywords}

Converter circuit, High frequency power converter, Switched-mode power supply

\begin{abstract}
This paper presents a bidirectional, four-quadrant flyback converter for use in direct audio power amplification. When compared to the standard Class-D switching-mode audio power amplifier with separate power supply, the proposed four-quadrant flyback converter provides simple and compact solution with high efficiency, higher level of integration, lower component count, less board space and eventually lower cost. Both peak and average current-mode control for use with 4Q flyback power converters are described and compared. Integrated magnetics is presented which simplifies the construction of the auxiliary power supplies for control biasing and isolated gate drives. The feasibility of the approach is proven on audio power amplifier prototype for subwoofer applications.
\end{abstract}

\section{Introduction}

In parallel with the performance improvement of the power electronics components in terms of higher power levels and switching speeds, new challenging application areas start to appear for the switching-mode power conversion. One of them is certainly the audio power amplification, where the switching-mode Class D audio power amplifiers become increasingly popular due to their efficiency, low losses, reduced volume and board space, with subsequent decrease in the product cost. This application area was ruled by the linear electronics amplifiers for many decades, but today they are leaving the scene since their poor efficiency and huge power losses are becoming major obstacle towards the trend of high-level product integration. Class D amplifiers are not without pitfalls either, since they are especially prone to EMC problems. However, the early success of the switching-mode audio power conversion on the market today shows that the Class D amplifiers are an emerging technology with a bright future.

One of the usually overseen benefits of the switching mode audio power conversion is the possibility of closely interconnecting the front-end switching-mode power supply and the Class D amplifier into a single integrated stage, since the switches in both aforementioned parts perform similar functions of power processing through switching and can be therefore multiplexed. This results in a highly integrated product with simplified power supply and no intermediate DC-bus, reduced component count, smaller volume, shrunk power conversion chain and even higher efficiency, which is sometimes referred as SICAM - SIngle Conversion 


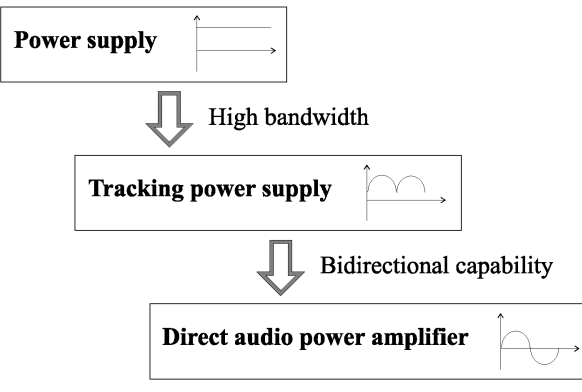

Fig. 1 SICAM roadmap

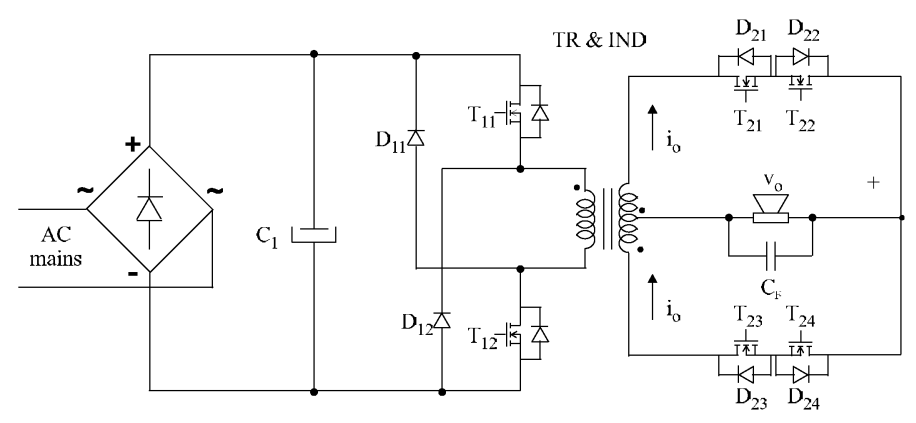

Fig. 2 Two-switch 4Q flyback SICAM

stage AMplifier [1],[2]. It is also quite appealing for the Active Transducer (AT) [3] approach for direct conversion of the mains power into acoustic output in one simplified topological stage, like in the active loudspeaker systems and dedicated subwoofer units. Obviously, these simplifications are complicating the control design and come on expense of slightly lower audio performance, but are nonetheless representing an interesting alternative. Since the prime mover in the low-end segment of the market is the product price, direct audio power amplifiers i.e. SICAMs are rather challenging to investigate as a possible way of cutting the costs.

\section{Four-quadrant flyback SICAM}

\section{Topology and operation principles}

The simplest way of developing direct audio conversion topologies is starting with a particular power supply scheme and extending its capabilities 1. Firstly, the power supply control bandwidth is increased over the intended power bandwidth i.e. over the highest frequency of the signal that is to be amplified, resulting in tracking power supply with variable DC output voltage. This is usually done by decreasing the size of the output lowpass filter so that its frequency response is flat over all the frequencies of interest and then drops rapidly to attenuate the switching harmonics. In order to complete the construction of the direct audio power amplifier, bidirectional power flow capability is added to the tracking power supply by replacing all the unidirectional components (for example, the secondary-side rectifiers) with bidirectional switches that can block voltage of either polarity and conduct current of either direction (for example, two series MOSFETs with common source connection).

Flyback converter presents the simplest isolated power supply topology, where the filtering inductor is actually integrated into the isolation transformer and represents means of transferring the energy from the primary-side voltage source to the secondary-side load. Consequently, the flyback converter saves the designer one magnetic component, but it increases the size and the stress exerted upon the other components, like the output capacitor that is to supply the whole load current for the periods when the main switch is turned on. On the other hand, there is just single-order filtering of the current switching harmonics at the output, performed solely by the output capacitor, which leads to substantial voltage ripple on the output. Therefore this topology is used only at lower power levels, when its benefits are most pronounced.

The two-switch four-quadrant (4Q) flyback SICAM is shown in Fig. 2. It is derived from the two-switch flyback converter, where the secondary side consists of two windings and two bidirectional switches: $T_{21}-T_{22}$ with parasitic diodes $D_{21}-D_{22}$ and $T_{23}-T_{24}$ with parasitic diodes $D_{23}-D_{24}$. The primary side stays essentially the same.

The amplifier is operated in a way that the primary side switches are turned on until enough energy has been stored in the magnetizing inductance of the flyback transformer, which is 


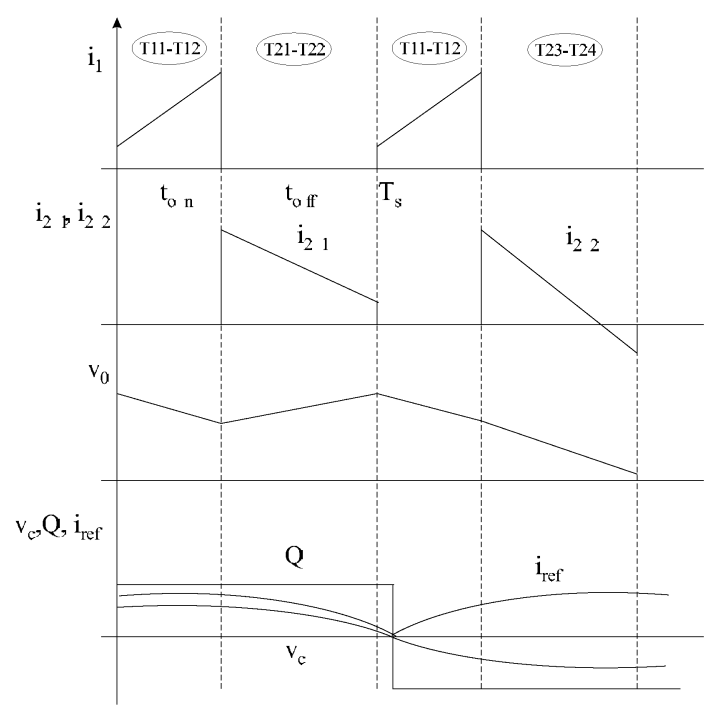

Fig. 3 Waveforms of the 4Q flyback SICAM

afterwards released either through $T_{21}-T_{22}$ or $T_{23}-T_{24}$ to charge the output capacitor to the desired voltage across the load. When the energy has been delivered to the load the current is allowed to reverse so that part of the capacitor charge is delivered back to the magnetizing inductance and returned to the primary side during the on-time of the main switches. This allows the flyback converter to operate in continuous conduction mode like a "rocking chair", where first the energy is delivered to the load side and then maybe it is partly returned back to the primary side. Some of the 4Q flyback waveforms are given in Fig. 3.

The 4Q flyback SICAM can be constructed as either single-switch or two-switch. In the practical implementations of single-switch DC-DC flyback converters, it is necessary to use a clamp on the primary side of the transformer to dissipate the energy stored in the primary-side leakage inductance. However, the voltage across the transformer during the off-time of the main switch can have either polarity and therefore the primary side clamp can be charged from the load side whenever the output voltage reflected to the primary side is higher than the clamp voltage. The two-switch 4Q flyback SICAM does not experience the same problem, since the transformer primary side during the off-time of the main switch is clamped to the rectified input voltage by using the two freewheeling diodes $D_{11}$ and $D_{12}$. This voltage is always bigger than the reflected load voltage since it is limited by the design i.e. the duty cycle is less than $50 \%$. Because of the same reason, the primary side switches do not need to have bidirectional voltage blocking capability, but must have bidirectional current capability (ex. MOSFETs) to allow continuous current mode operation. Taking into account the additional benefit that the two-switch flyback converter requires switches with just half the voltage blocking capability of the one-switch flyback converter, it can be concluded that the two-switch topology represents a very feasible choice for bidirectional converters from cost and implementation perspective.

The disadvantages of the flyback converter with regard to the large output capacitance needed for filtering the switching harmonics of the inductor current become even more pronounced in its bidirectional implementation. The output capacitor is supplying the whole load current during the on-period of the main switches, therefore the demands set upon it are very stringent. Due to the bipolar nature of the output voltage, the unipolar aluminium electrolytic type capacitors found in conventional switching-mode power supplies cannot be used and the size of the output section is inevitably increased. Therefore, the flyback topology for SICAMs is limited to low power levels. 
The most difficult part of the design of the 4Q flyback SICAM power section is the selection of the output capacitor and the flyback transformer magnetizing inductance. The minimum output capacitor is determined by the desired maximum output voltage ripple:

$$
C_{\min }=\frac{Q}{\Delta U_{\max }}=\frac{I_{o, \max } D_{\max }}{\Delta U_{\max } f_{s}}
$$

where $I_{o, \max }$ is the maximum load current, $D_{\max }$ is the maximum duty cycle, $\Delta U_{\max }$ is the maximum voltage ripple and $f_{s}$ is the switching frequency.

Although $C_{\min }$ is the minimum output capacitance needed with regard to the output voltage ripple limit, it is also the optimal since increasing that value significantly over $C_{\min }$ will result in slower response. It will be shown in the next section that the actual output voltage ripple can also depend on the bandwidth of the outer voltage loop.

Choosing the optimal value of the inductance represents slightly greater challenge. One way of choosing the magnetizing inductance is by determining the maximum slope of the average output current $i_{o}=I_{o} \sin (2 \pi f t)$ and associated average inductor current $i_{L}=i_{o} /(1-D)$ :

$$
\begin{aligned}
S_{I_{o}, \max } & =\left.2 \pi f_{\max } I_{o} \cos \left(2 \pi f_{\text {max }} t\right)\right|_{t=0}=2 \pi f_{\max } I_{o} \\
S_{I_{L}, \max } & =\frac{S_{I_{o}, \max }}{1-D_{\max }}
\end{aligned}
$$

and choosing the instantaneous rising slope of the inductor current $V_{g} / L$ to be at least 20 times higher than the average inductor current slope $S_{I_{L}, \max }$.

The other possibility for selecting the magnetizing inductance is by noting that it is limiting the minimum frequency of the right-half plane zero $f_{R H P Z}[4]$ :

$$
f_{R H P Z, \min }=\frac{D_{\min }^{\prime 2} R}{2 \pi D_{\max } L_{\max }}=0.5 \frac{R}{2 \pi L_{\max }}
$$

It is known that the maximum usable control bandwidth of a system is limited to approximately one third of the frequency of the right half-plane zero [5] and one tenth of the switching frequency $f_{s}$. This leads for example to the following selection rule:

$$
L_{\text {max }}=0.5 \frac{R}{2 \pi \cdot f_{R H P Z, \min }}=0.5 \frac{R}{2 \pi \cdot 0.3 f_{s}}
$$

Slightly different 4Q flyback converter has been presented in [6], where it is built around a dedicated chipset for ring generators. Its operation principles differ from the proposed simple solution, since during the off-time of the main switch, the secondary side switches are operated in a PWM manner and energy is transferred to the primary side via a separate winding with series rectifier. Another difference is that the secondary side switches can block both voltage polarities, but the current can only be unidirectional and the flyback converter operates in discontinuous conduction mode without the aforementioned "rocking chair" effect.

\section{Control of $4 Q$ flyback SICAM}

The selection of the control algorithm for the 4Q flyback SICAM represents a trade-off among many different objectives, like stability, low distortion and simplicity of implementation.

The simplest way of control is single loop output voltage control, where the only feedback is taken from the load voltage and is used afterwards to derive the main switch duty cycle. The main disadvantages with this approach are the involved second order transfer function with the continuous mode operation, which makes it very difficult to make satisfactory control synthesis, as well as the inability to correct for input line perturbations until changes are observed in the output voltage. 
Much better performance can be achieved with current mode control, where the inner current loop and the outer voltage loop are simultaneously used to derive the duty cycle of the main switch. While the voltage loop is always taken from the load, the selection of current for closing the inner current loop can ask for careful consideration. In the buck derived topologies, where the second order LC output filter is placed across the load, the inductor current is essentially the load current and by controlling directly the inductor current, the dynamics of the load current is being governed too. On the other hand, the flyback output current is different than the inductor current by a factor which depends on the duty cycle and it can be disputed which of these two is to be controlled. However, if the goal of the current selection is to simplify the control synthesis of the outer voltage loop, then obviously controlling the inductor current helps move the pole associated with the inductor to higher frequencies. Even more, sensing inductor current is sometimes easier due to its continuity and can be done in many different ways, some being more simple than the others. Therefore, in the following sections will be dealt only with inductor current control in the inner loop.

There are many different ways to implement current mode control, among which the peak and average current mode control are probably the most applicable ones. They have some distinct advantages and pitfalls, which define their specific application areas. They can be both used in 4Q flyback SICAMs and their implementation is subject of the next few sections.

\section{Peak current mode control}

The block scheme of the control section of the 4Q flyback SICAM with peak current-mode control is given in Fig. 4. As shown, it is a cascade system where the inner loop sets the inductor current and the outer loop controls the output voltage. The absolute value of the control voltage $v_{c}$ gives the reference current $i_{r e f}$, while its sign given by the comparator i.e. 1-bit quantizer $\mathrm{Q}$ determines which secondary-side bidirectional switch will be turned on during the off-time of the primary side switches. The reference current $i_{r e f}$ is subsequently compared with the instantaneous value of the switch current to determine the switching-off instant, resulting in peak current mode control. Beside the aforementioned simplification of the transfer function, the peak current mode control yields a simple solution with fast response, high rejection ratio of the input voltage perturbations and cycle-by-cycle current limiting.

In order to avoid output voltage zero-crossing distortion, there must be some minimum inductor current delivered to the output even at idle. During this idling time, the 1-bit quantizer

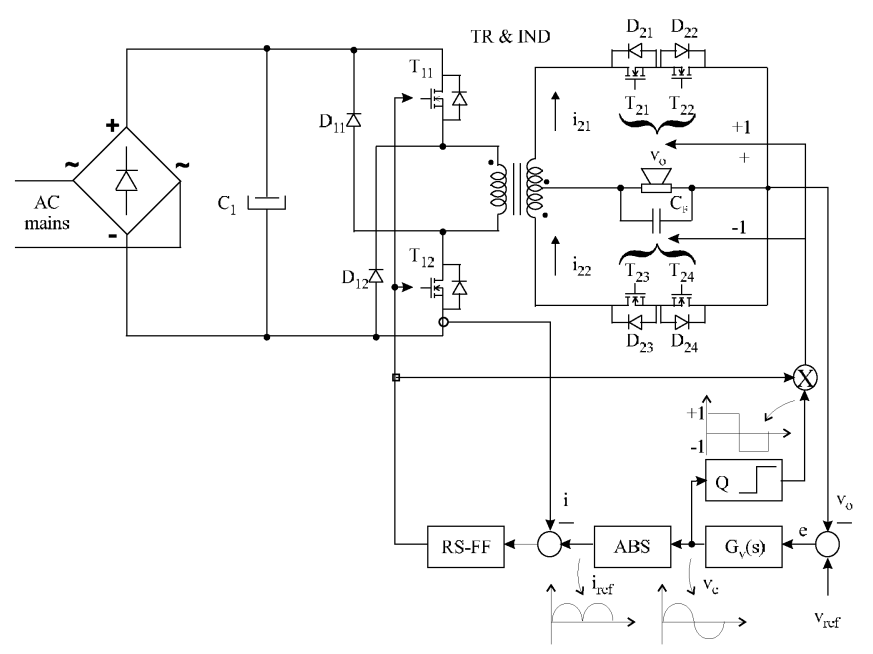

Fig. 4 Peak current-mode control

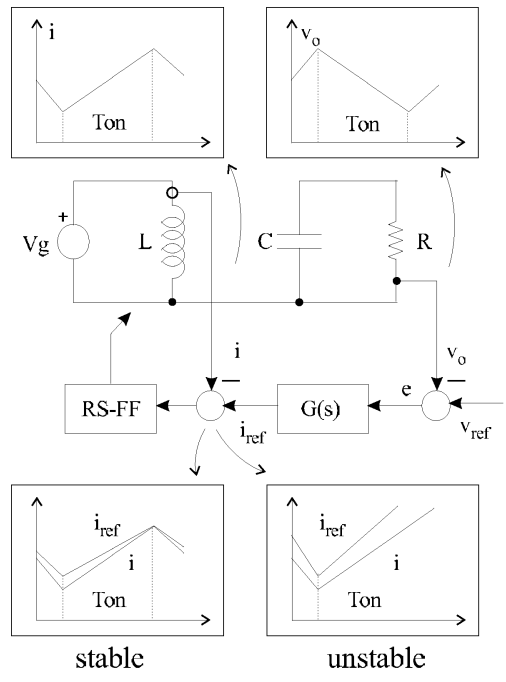

Fig. 5 Slope matching 
is likely to be stuck in a certain state of the output stage, which means that the output voltage will continue to increase in one direction. With other words, 4Q flyback SICAM does not have any stable equilibrium state corresponding to idle, which represents a strong contrast to the conventional Class D audio power amplifier, where the duty cycle of $50 \%$ assures zero average output voltage with certain predetermined output filter ripple. In the 4Q flyback SICAM it is up to the outer voltage loop to sense this excessive voltage ripple and prohibit it by changing the sign of the control voltage $v_{c}$ and the associated output stage state. Therefore, in this implementation it is very important to have shorter time delays within the control loop and provide high control bandwidth, by increasing the gain of the phase compensator $G_{v}(s)$. The highest possible gain of the compensator at the switching frequency, which does not cause instability is determined by matching the up-slope of the increasing inductor current and the down-slope of the falling output voltage, like shown in Fig. 5:

$$
\begin{aligned}
R_{C S} \frac{V_{g}}{L} & =A \frac{v_{o}}{R C} \\
A_{\max } & =\frac{R_{C S} \cdot R \cdot C \cdot V_{g, \text { min }}}{L \cdot V_{o, \max }}
\end{aligned}
$$

where $R_{C S}$ is the current sense resistor, $V_{g}$ is the DC source voltage, $R$ is the load resistance and $A$ is the gain from the output voltage to the input of the current controller at $f_{s}$.

Design of the phase compensator $G_{v}(s)$ is performed by shaping the overall loop transfer function $L$ so that both sufficient gain throughout the desired signal frequency range and high bandwidth are obtained. The plotting of the loop transfer function is alleviated by assuming that the inner current loop operates ideally and the inductor current $i_{L}$ is following the reference current $i_{\text {ref }}$ with a high degree of accuracy, although this essentially depends on the level of inductor current ripple $\Delta i_{L}$. The loop gain $L$ and its constitutive parts are:

$$
\begin{aligned}
L(s) & =G_{v}(s) G_{i_{L} c}(s) G_{o i_{L}}(s) G_{o p t o}(s) H_{v}(s) \\
G_{v}(s) & =K\left(1+\frac{1}{s \tau_{i}}\right) \\
G_{i_{L} c}(s) & =\frac{1}{n R_{C S} K_{C S}} \\
G_{o i_{L}}(s) & =\frac{R}{1+s R C} \\
G_{o p t o}(s) & =K_{i} \\
H_{v}(s) & =\frac{1}{K_{v}}
\end{aligned}
$$

where the meaning of the corresponding transfer functions is given in Fig. 6.

It is interesting to note that, although the $4 \mathrm{Q}$ flyback converter has much simpler power section than the Class D amplifier with separate power supply, the control section shown in Fig. 4 tends to be involved and is further aggravated by the need for crossing the isolation barrier. The way this is usually done in a conventional flyback SMPS is to transfer the current reference using a simple optocoupler, which often has a highly nonlinear current transfer ratio (CTR) when looked in a large signal sense. On the other hand, the operation of a 4Q flyback SICAM involves largely varying control signals and the current reference $i_{\text {ref }}$ must be transferred to the isolated primary side with high degree of accuracy to avoid excessive distortion. The easiest way to do that is to use a linear optocoupler with servo loop built around it for linearizing its CTR. This results in a combined primary and secondary side control, where the phase compensator of the outer voltage loop resides on the secondary 


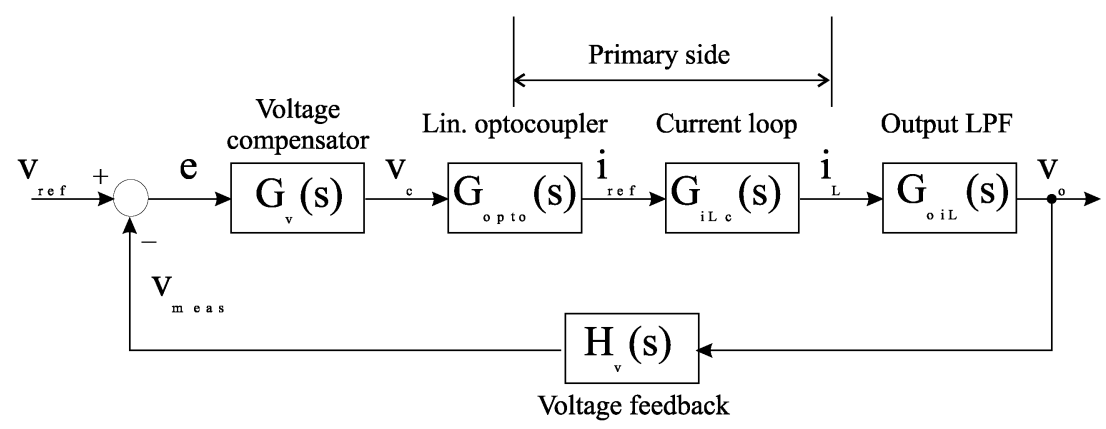

Fig. 6 Peak current mode control block diagram

side and the phase compensator of the inner current loop is implemented on the primary side together with the sensing of the switch current. As an option, switch current can be sensed and transferred to the secondary side with a current transformer, so that all the control is located on the secondary side. However, the gate drive signals for the primary side switches still need to be transferred back with a separate pulse transformer, thus complicating this option even further.

\section{Average current-mode control}

Beside the aforementioned advantages of the peak current-mode control with regard to its simplicity, speed and cycle-be-cycle current limiting, there are also some serious drawbacks. The most important drawback is the fact that controlling the peak value of the inductor current does not necessarily mean that the average inductor current value follows the current reference, which becomes especially pronounced in the continuous mode operation with large ripple current and even more in the discontinuous mode. For example, if the peak inductor current follows perfectly the sinewave current reference of the audio amplifier, the actual average inductor current is likely to be much different than the reference, depending on the amount of current ripple. As a side effect of this problem, the low frequency gain of the peak current mode controller is limited and does not guarantee high performance throughout the whole power bandwidth.

Operation of the 4Q flyback SICAM with large inductor ripple current is desired for at least two reasons. Firstly, large ripple is a result of low flyback transformer inductance which allows for much smaller size of the magnetics. On the other hand, low inductance is also a must, since for proper operation of the audio power amplifier the current level must be changed sufficiently fast to achieve the desired dynamics of the converter. This means that correct control of the average inductor current with low distortion will be nearly impossible with peak current mode control.

In order to reduce the distortion, average current mode control can be implemented and optimized by slope matching for achieving optimal speed of the response [7], comparable to peak current mode control. By proper design of the phase compensator in the inner current loop, sufficient gain can be provided even at low frequencies where peak current mode control is unable to deliver the same performance when large inductor current ripple is present.

Average current mode control also enables use of non-dissipative techniques for inductor current sensing, in contrast to the usual current sense resistor technique. The inductor current can be estimated by putting additional winding on the flyback transformer and ideally integrating the transformer voltage with electronic components. In this case all the control can be done on the secondary side, and it is just the main switches gate drive that needs to be transferred to the primary side. In practice, integration of the transformer voltage is impossible due to 


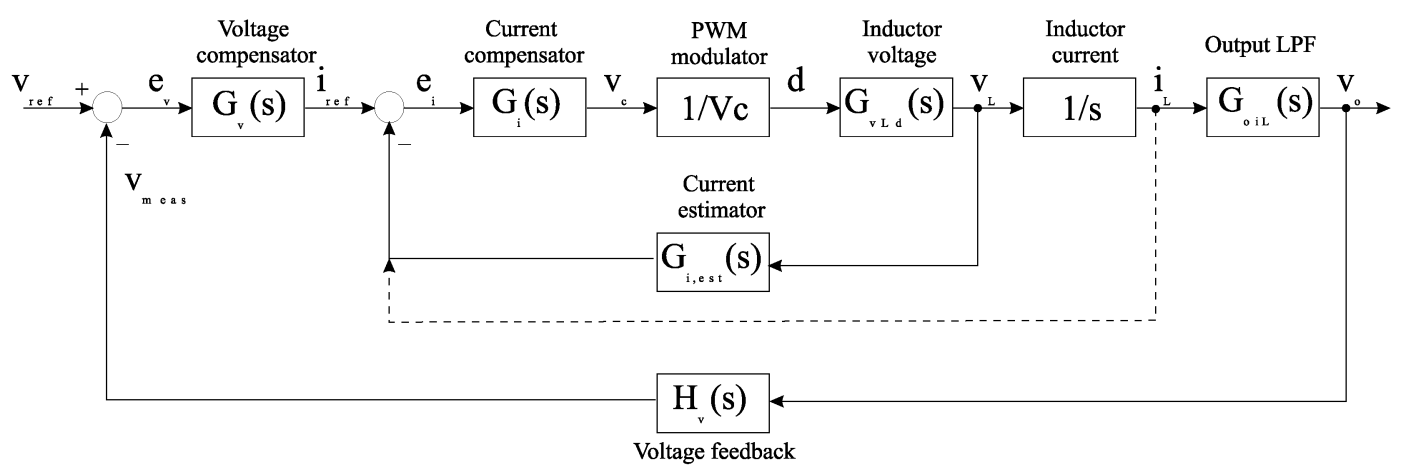

Fig. 7 Average current mode control block diagram

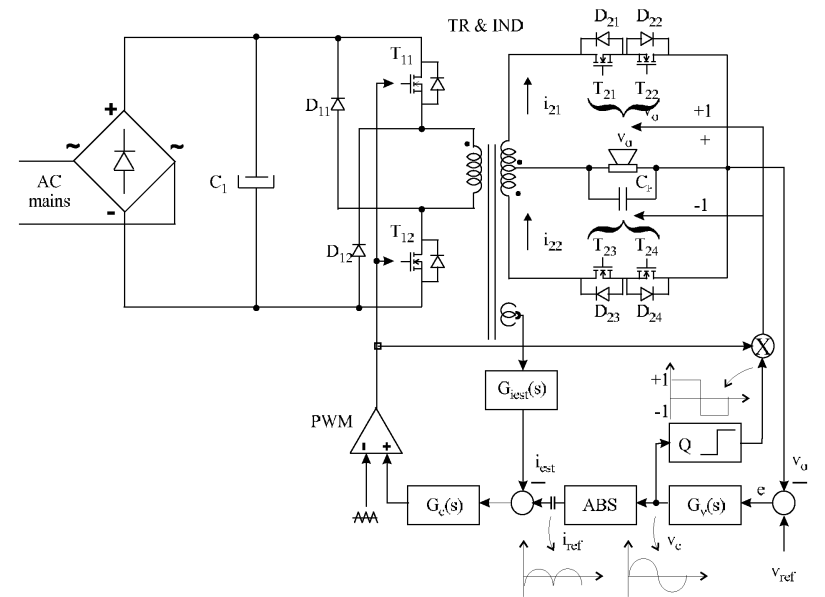

Fig. 8 Average current-mode control

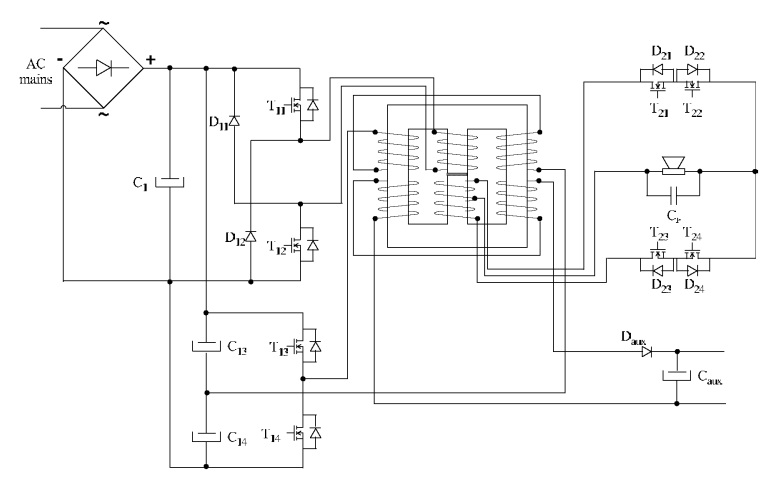

Fig. 9 Integrated magnetics

the non-zero offset of operational amplifiers, and what is usually done is low pass filtering to derive exactly the high frequency content of the inductor current. This essentially means that the DC value of the inductor current with this method can not be recovered. Thus the low frequency performance of the control circuit is left to the outer voltage loop. The control block diagram of the 4Q flyback SICAM with average current mode control is given in Fig. 7 and the complete schematic is given in Fig. 8. Inductor current estimator transfer function is:

$$
G_{i, e s t}(s)=K_{i, e s t} \cdot \frac{N_{e}}{N_{l}} \cdot \frac{1}{1+s \tau_{i, e s t}}
$$

where $K_{i, e s t}$ and $\tau_{i, e s t}$ represent the estimator gain and time constant, and $N_{e}$ and $N_{l}$ are the estimator and inductor number of turns respectively.

\section{Integrated magnetics for $4 \mathrm{Q}$ flyback SICAM}

The 4Q flyback SICAM belongs to the group of SICAMs with modulated transformer voltages, which means that the power flow through the main winding of the power transformer depends on the amplitude of the signal being reproduced. This approach does not allow for continuous and constant power flow to the auxiliary power supplies for control biasing and isolated gate drive of the secondary side bidirectional switches.

Although the aforementioned problem can be alleviated by using separate mains transformers or small isolated SMPSs for providing the auxiliary voltages, much more elegant solution can be achieved through integrated magnetics, like shown in Fig. 9. The auxiliary half-bridge converter consisting from switches $T_{13}, T_{14}$ and capacitors $C_{13}, C_{14}$ applies $\mathrm{HF}$ voltage on the 
two in series connected identical auxiliary windings on the outer legs of the main transformer. The flux created from both of them is the same and flows entirely in the outer legs, while the electromotive forces created by the center leg flux are equal and ideally cancel each other in the auxiliary windings. Thus the two magnetic structures on the same core are completely independent in their operation. Two series connected auxiliary windings on the secondary side are used to derive all the auxiliary voltages, operating as a DC transformer for simplicity or with variable duty cycle in some kind of standard SMPS configuration.

\section{Measurements on the prototype}

To test the feasibility of the approach, an $80 \mathrm{~W}$ into $8 \Omega$ two-switch 4Q flyback subwoofer SICAM prototype with average current-mode control was constructed and its photo is shown in Fig. 10. The switching frequency is set to $f_{s}=150 \mathrm{kHz}$. The prototype resembles the structure shown in Fig. 8 and it incorporates the aforementioned integrated magnetics for deriving all the auxiliary voltages on the secondary side, as in Fig. 9.

Fig. 11 shows in detail the operation of the $4 \mathrm{Q}$ flyback SICAM with zero reference. The short on-periods of the primary side switches represent some minimum allowed on-time being intentionally inserted even with no error voltage on the input of the controller, just to avoid zero-crossing distortion of the output voltage. The state of the one-bit quantizer $Q$ determines the secondary side bidirectional switch, which will be turned on right after the primary side switches seize conducting. The selected bidirectional switch is turned on for the rest of the time until the primary side switches conduct again, although the state of the one-bit quantizer $\mathrm{Q}$ maybe has changed in the meantime. Due to the fast outer voltage loop even this small ripple in the output voltage is sensed and is causing an immediate change in the control voltage sign, so that the selected bidirectional output switch alternates each period to yield minimum ripple voltage. Making the outer voltage loop slow will cause the output voltage ripple to be large, since the guaranteed minimum inductor current with the same output switch turned on during few periods will continue charging the output capacitor to large values.

Fig. 12 shows the operation of the 4Q flyback SICAM at output power of $P_{o}=50 \mathrm{~W}$ with $200 \mathrm{~Hz}$ reference voltage.

The efficiency of the prototype is given in Fig. 13. This particular realization of the 4Q flyback SICAM does not have very high efficiency, but this is likely to be improved in the next prototype.

The presented results prove the feasibility of the 4Q flyback SICAM for audio power amplification. Its application is intended for lower power levels and lower audio frequency range, predominantly subwoofer applications.

\section{Conclusion}

In this paper, a 4Q flyback converter for direct audio power amplification with unique operation principle has been presented. It is also shown how peak and average current mode control can be utilized to improve converter performance. New integrated magnetics is proposed for the 4Q flyback SICAM, which fits both the main and the auxiliary transformers on the same magnetic core. The experience gained from the prototype proved that this compact power conversion topology has the benefits of being simple and having satisfactory efficiency combined with reduced volume, high power density, low component count and subsequently low cost, which makes it appealing for the low-power and low-end audio power amplifiers. 


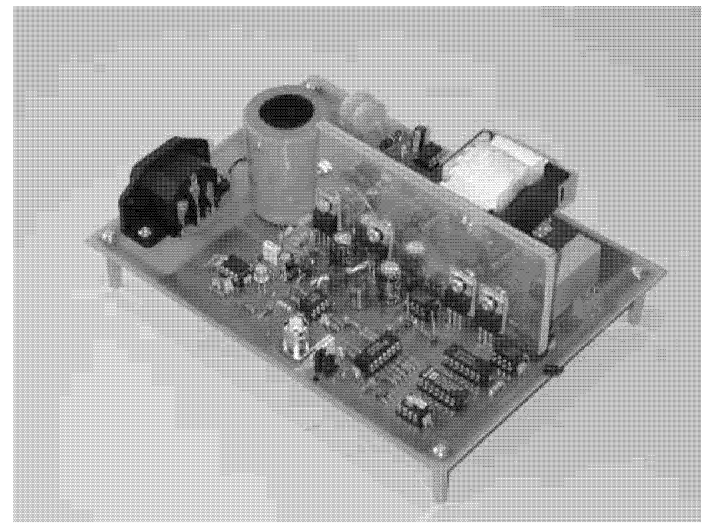

Fig. 10 4Q flyback SICAM prototype

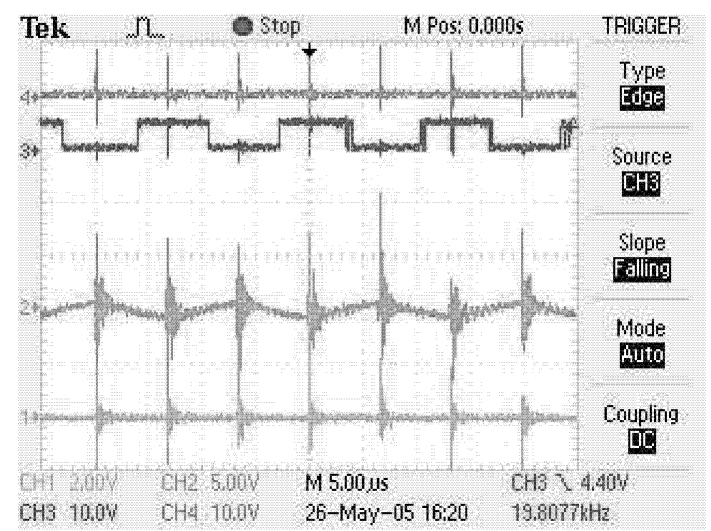

Fig. 11 Waveforms with zero reference: 1) ref. voltage $\left.v_{r e f}, 2\right)$ output voltage $v_{o}$, 3) comparator $Q$ output, 4) primary gate drive

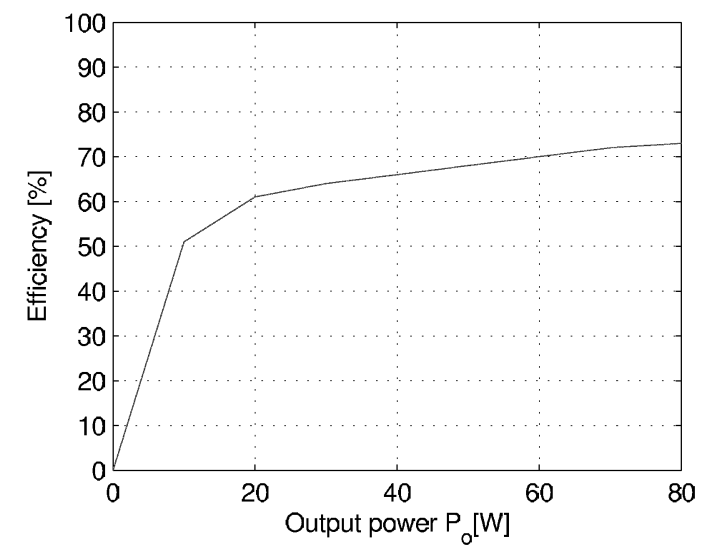

Fig. 13 Efficiency of the 4Q flyback SICAM

$200 \mathrm{~Hz}$ reference: 1) ref. voltage $v_{r e f}$, 2) output voltage $\left.v_{o}, 3\right)$ comparator $\mathrm{Q}$ output, 4) primary gate drive

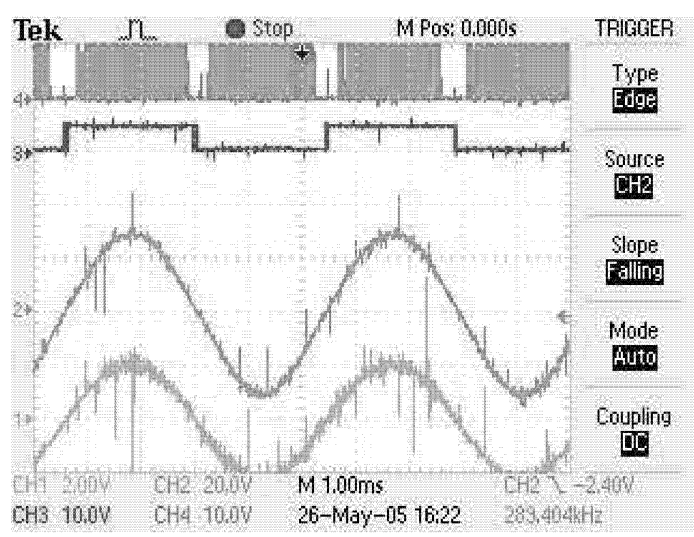

Fig. 12 Waveforms at $P_{o}=50 \mathrm{~W}$ with

\section{References}

[1]. P. Ljušev and M. Andersen, "Approaches to building single-stage ac/ac conversion switch-mode audio power amplifiers," in Proc. 11th International Power Electronics and Motion Control conference EPE-PEMC 2004, (Riga, Latvia), September 2-4 2004.

[2]. P. Ljušev and M. Andersen, "Safe-commutation principle for direct single-phase ac-ac converters for use in audio power amplification," in Proc. Nordic Workshop on Power and Industrial Electronics NORPIE 2004, (Trondheim, Norway), June 14-16 2004.

[3]. K. Nielsen and L. M. Fenger, "The active pulse modulated transducer (at) a novel audio power conversion system architecture," in 115th Convention of the Audio Engineering Society, AES Proceedings, October 10-13 2003. Preprint 5866.

[4]. R. W. Erickson and D. Maksimović, Fundamentals of Power Electronics. Kluwer Academic Publishers, 2001. Second edition.

[5]. L. H. Dixon, "Control loop cookbook," Tech. Rep. SLUP113, Unitrode Power Supply Design Seminar SEM1100, 1996.

[6]. D. Dalal, "A unique four quadrant flyback converter," Tech. Rep. SLUP116, Unitrode Power Supply Design Seminar SEM1200, 1997.

[7]. L. H. Dixon, "Average current mode control of switching power supplies," Tech. Rep. SLUP091, Unitrode Power Supply Design Seminar SEM700, 1990. 